\title{
Grandes esperanças: tribunais do acidente médico na República Popular da China
}

\author{
Great expectations: medical accident tribunals in the Popular Republic of China
}

Grandes esperanzas: tribunales del accidente médico en la Republica Popular de China

\author{
Vera Lúcia Raposo ${ }^{1}$ \\ Man Teng long ${ }^{2}$
}

RESUMO: Devido às profundas mudanças económicas e sociais na China a prestação de cuidados de saúde enfrenta sérias dificuldades para satisfazer as necessidades dos pacientes, conduzindo, pois, a frequentes conflitos entre pacientes e médicos e/ou estabelecimentos de cuidados de saúde. Uma vez que os tribunais comuns parecem incapazes de resolver os litígios médicos de uma forma considerada satisfatória para ambas as partes, o Governo Chinês criou os tribunais do acidente médico. Estes tribunais são caracterizados por duas notas principais: por um lado a sua composição, dado que, e ao contrário dos tribunais judiciais, são compostos por decisores com conhecimentos médicos; por outro lado, o facto de a actividade dos tribunais do acidente médico se restringir ao campo da responsabilidade médica, sendo que esta especialização Ihes permite decidir os casos de uma forma mais expedita e supostamente mais justa. Contudo, e apesar do grande desenvolvimento representado pelos tribunais do acidente médico, eles representam apenas uma pequena peça da grande reforma exigida pelos conflitos médicos que têm lugar por toda a China.

Palavras-chave: Tribunais do Acidente Médico. China. Responsabilidade Médica. Direitos Dos Pacientes. Conflitos Médicos.

ABSTRACT: Due to deep economic and social changes in China health care delivery faces severe difficulties in order to satisfy the patient's needs, thus leading to frequent conflict between patients and health care facilities and/or doctors. Since regular courts seem unable to solve medical litigation cases in a way considered satisfactory for both parties Chinese government created the so called "medical accident tribunals". These courts are characterised by two main notes: on the one hand, their composition, since, unlike regular courts, they are composed by deciders with medical expertise; on the other hand, the fact that the activity developed by these courts is restricted to the field of medical liability, thus, this specialization allows them to decide faster and supposable in a more just way.

\footnotetext{
1 Professora Assistente da Faculdade de Direito da Universidade de Macau e Professora Auxiliar da Faculdade de Direito da Universidade de Coimbra (vraposo@umac.mo). O presente trabalho resulta de uma investigação financiada pela Universidade de Macau (MYRG2015-00008-FLL). Email: manteng.iong@gmail.com.

2 Jurista e Notário Privativo dos Serviços de Saúde de Macau, Licenciado em Direito pela Faculdade de Direito da Universidade Nova de Lisboa; Mestre em Ciências Jurídicas pela Faculdade de Direito da Universidade de Macau. Email: manteng.iong@gmail.com.
} 
However, and despite the main development that medical accident courts represent, they are just a small piece of the main reform required by medical conflicts around China.

Keywords: Medical Accident Tribunals. China. Medical Liability. Patient's Rights. Medical Conflicts.

RESUMEN: Debido a los profundos cambios económicos y sociales en China la prestación de atención de salud está enfrentando serias dificultades para satisfacer las necesidades de los pacientes, lo que lleva a frecuentes conflictos entre pacientes y médicos y/o centros de salud.Desde los tribunales ordinarios parecen incapaces de dar solución a las controversias médicas de manera satisfactoria, el gobierno chino ha creado los tribunales del accidente médico. Estos tribunales se caracterizan por dos notas claves: por un lado, su composición, que están compuestas por los encargados de la adopción de decisiones con conocimientos médicos; por otro lado, el hecho de que las actividades de los tribunales del accidente médico si restringir el ámbito de la responsabilidad médica, y que esta especialización les permite decidir los casos de manera más rapida y e más justo. Sin embargo, y a pesar del gran desarrollo representada por los tribunales del accidente médico, sólo representan una pequeña parte de la gran reforma médica requerida por los conflictos que tienen I en China.

Palabras-Ilave: Tribunales de accidentes médicos. China. La responsabilidad médica. Los derechos de los pacientes. Conflictos médicos.

\section{Introdução}

\section{Identificação dos focos de conflitos médicos}

Nos últimos anos a mercantilização apoderou-se da prestação de cuidados de saúde na República Popular da China. O modelo tradicional que facultava serviços médicos à população de forma totalmente gratuita, ou pelo menos subsidiada pelo Estado na sua quase totalidade, deu lugar a um outro modelo em que boa parte dos gastos de saúde correm por conta do paciente. Por sua vez, a drástica redução de subvenções públicas obrigou os hospitais a encontrar outras formas de maximizar os recursos e de obter novas fontes de financiamento, enveredando por métodos que têm suscitado a crítica dos pacientes e dos poderes públicos ${ }^{3}$ (1) (2) (3).

Este cenário conduziu a várias consequências que têm preocupado as autoridades chinesas e às quais se procura dar uma solução (1) (4) (que, porém, não se adivinha fácil, dada a crescente procura de cuidados de saúde e o novo paradigma que lhes subjaz).

\footnotetext{
3 Sobre a forma como a qualidade dos cuidados de saúde diminui substancialmente por força da mercantilização da saúde na República Popular da China,
} 
Antes de mais, o facto de o pagamento ser a maior parte das vezes custeado pelo próprio paciente aumentou exponencialmente as suas expectativas: quem paga exige e os pacientes chineses exigem quiçá demais dos seus médicos, reagindo violentamente quando as suas expectativas saem goradas (5) (6) (7) Daqui decorre que muitos pacientes insatisfeitos e seus familiares optaram por abdicar dos tribunais e recorrer a vias menos ortodoxas e por vezes violentas, que ficaram conhecidas como "distúrbios dos cuidados de saúde" (“醫閏”) 4 . Os distúrbios dos cuidados de saúde são um conjunto de medidas mais ou menos agressivas que o paciente e/ou o seu familiar utilizam contra hospitais ou profissionais de saúde, tais como a realização do luto em hospitais, a adopção de comportamentos que dificultam ou impedem a prestação de cuidados de saúde a outros pacientes, a destruição de patrimónios de hospitais e mesmo ataques aos profissionais de saúde

Por outro lado, os casos clínicos chegam aos médicos em estádios cada vez mais avançado, o que dificulta a sua recuperação. Trata-se de uma outra consequência do facto dos cuidados de saúde serem maioritariamente pagos pelos pacientes e de estes frequentemente se debaterem com dificuldades económicas, pelo que vão adiando a visita ao médico até ao momento em que a podem custear. Porém, os pacientes não compreendem que o insucesso do tratamento se fica as mais das vezes a dever ao grau de desenvolvimento da patologia e, ao invés, culpam os médicos pelo fracasso do tratamento.

A falta de comunicação entre médico e paciente é outro elemento a ter em conta na prestação de cuidados de saúde da República Popular da China. Não só ficam por satisfazer as exigências do consentimento informado - aliás, legalmente estipuladas ${ }^{5}$ como o desconhecimento face aos actos realizados e respectivos efeitos reforça as expectativas do paciente e aumenta a sua frustração em caso de insucesso.

Por outro lado, ainda, as enormes discrepâncias nos cuidados prestados agudizam a situação. A qualidade dos serviços médicos nos grandes hospitais urbanos em nada se

\footnotetext{
${ }^{4}$ Todas as traduções de chinês para português apresentadas no presente artigo expressam traduções livres da exclusiva responsabilidade dos autores.

5 Por exemplo, veja-se o Artigo 33 dos Regulamentos Administrativos sobre Instituições Médicas (醫療機構管理條例) e o Artigo 26 da Lei sobre a Prática Médica da República Popular da China (中華人民共和國執業醫師法).
} 
compara com o nível que caracteriza os centros de saúde rurais, o que cria tensões entre a população e afasta os mais pobres de cuidados básicos de saúde (8)

A isto acresce que o recuo do financiamento público conduziu os hospitais à procura de métodos alternativos de financiamento, quase sempre em detrimento do paciente. O recurso a um número excessivo de exames e cirurgias e a escolha de tratamentos mais caros (9) - ainda que não necessariamente mais eficazes - tornaram os cuidados de saúde proibitivamente caros; porém, não de melhor qualidade.

Apesar do preço, o certo é que os hospitais estão sempre sobrelotados, não apenas por pacientes, mas também pelos seus familiares, que muitas vezes os acompanham vindos de zonas rurais, o que torna os hospitais - sobretudo os urbanos - em centros muito movimentados, onde o número de pacientes ultrapassa largamente o número de médicos. Por conseguinte, a atenção dispensada a cada paciente é escassa e o follow up é raro.

A tudo isto acresce uma crescente desconfiança nos serviços de saúde, que se sabe serem povoados pela corrupção e por outras práticas questionáveis. Os pacientes acreditam que os médicos são movidos por intuitos lucrativos e, por conseguinte, revelamse cépticos ao longo do tratamento e impiedosos quando o seu desfecho não agrada.

A tudo isto que ficou dito há ainda que acrescentar outros factores que agravam a relação entre prestador de cuidados de saúde e paciente. Por um lado, a ausência de consentimento informado e, em boa verdade, de qualquer comunicação relevante (10). Por outro lado, as dificuldades do paciente em aceder ao processo clinico, a sua incompletude e falta de rigor ${ }^{6}$. Por outro lado, ainda, as dificuldades do sistema de resolução de conflitos médicos, que será o tema do presente artigo ${ }^{7}$.

\section{A resolução de litígios médicos}

Face à situação descrita não espanta que os litígios médicos proliferem na República Popular da China. Porém, a sua resolução não se afigura tarefa fácil, dado que

\footnotetext{
6 廣州中院發佈近五年醫療糾紛訴訟白皮書, Legal Daily, 26 maio 2015 [Acesso em 26 jan 2016]. Disponível em: http://www.legaldaily.com.cn/Court/content/2015-05/26/content_6097699.htm?node=53956

${ }^{7}$ Fazemos notar que todas as questões aqui afloradas revelam substancial interesse para o tema em análise, sobretudo tendo em vista a recente reforma legal em sede de responsabilidade civil operada em 2012 na República Popular da China. Porém, dada a sua complexidade não trataremos delas no presente artigo.
} 
a maioria dos juízes não é especialista em ciência médica, nem dispõe de conhecimento suficiente desta matéria para resolver satisfatoriamente os litígios de responsabilidade médica. Para colmatar esta lacuna muitas decisões judiciais acabam por se fundar mais nos relatórios dos peritos médicos do que nas apreciações jurídicas dos juízes ${ }^{8}$, o que deu azo à critica de que o julgamento estaria a ser feito pelos peritos e não pelos juízes. $O$ escasso conhecimento dos decisores sobre as particularidades da responsabilidade médica influenciou negativamente a resolução dos conflitos entre pacientes e profissionais de saúde e, do mesmo passo, deteriorou a confiança dos pacientes quer no aparelho jurídico quer nos serviços de saúde.

Porém, não se conclua daqui que as decisões judiciais sistematicamente beneficiem os prestadores de saúde. Bem pelo contrário, pois porventura como resultado da escassez de conhecimentos jurídicos sobre a matéria, os juízes acabam por se rever na fragilidade do paciente e, consequentemente, muitas vezes atribuem aos prestadores de cuidados de saúde mais responsabilidades do que aquelas que lhes cabem. Por força de decisões judiciais desta natureza muitos dos profissionais de saúde acabam por adoptar procedimentos típicos da dita medicina defensiva (11) e por afastar novos e mais eficazes tratamentos em favor de procedimentos mais tradicionais, por vezes já ultrapassados.

Numa tentativa de apaziguamento deste estado de coisas em várias cidades da República Popular da China foi proposta a criação dos chamados tribunais do acidente médico ${ }^{9}$ (“醫事法庭”). O seu propósito é resolver as disputas médicas de uma forma concentrada (isto é, sem se dispersar por outras questões), minorar a desconfiança dos pacientes e seus familiares no que toca aos julgamentos dos tribunais judiciais e, consequentemente, conduzir à eliminação gradual dos distúrbios dos cuidados de saúde.

\footnotetext{
8 廣州中院發布近五年醫療糾紛訴訟白皮書, Cit.

9 Esta foi a tradução pela qual os autores optaram, embora se reconheça que o termo "tribunais do erro médico" pudesse ser igualmente correcta. Note-se que qualquer destas designações apela a expressões que no léxico jurídico português não implicam sanções jurídicas em sede de responsabilidade médica. De facto, quer o erro quer o acidente se referem a quadros de actuação não culposa por parte do agente, à qual, por conseguinte, não corresponde qualquer imputação subjectiva em termos jurídicos (cfr. Vera Lúcia Raposo, Do Ato Médico ao Problema Jurídico (Breves Notas sobre o Acolhimento da Responsabilidade Médica Civil e Profissional na Jurisprudência Nacional), Almedina, Coimbra, 2013, p. 13 ff.). Porém, dado que estas parecem ser as expressões usadas na República Popular da China para referir os casos que dão origem a responsabilidade médica, decidimos respeitar esta especificidade jurídica e linguística.
} 


\section{Evolução histórica e estatuto Jurídico dos tribunais do acidente médico}

A existência dos tribunais do acidente médico não é uma aquisição recente, dado que já em 2001 fora constituído um "tribunal colegial de disputa médica" (“醫療糾紛合議庭”) no Tribunal Popular de NanJingShi QuinHuai (“南京市秦淮區人民法院”) ${ }^{10}$, o qual correspondia sensivelmente aos tribunais do acidente médico referidos neste estudo, não obstante a diferença de designação entre ambos.

Esta primeira tentativa não deu imediatamente azo a estruturas semelhantes e só a partir de 2013 começaram a surgir os actuais tribunais do acidente médico: a 13 de Março de 2013 surgiu "um juízo colegial para julgamento profissional de disputa médica" (“醫療糾紛專業審判合議庭”) no Tribunal Popular Intermédio de WuHan (“武漢市中級人民法院”) 11 ; no início de Julho de 2014, na cidade Mian Yang foram criados tribunais do acidente médico no Tribunal Popular Intermédio de Mian Yang Shi (“綿陽市中級人民法院”), no Tribunal Popular Distrital de FuCheng (“涪城區人民法院”) e no Tribunal Popular Distrital de You Xian (“遊仙區人民法院”)"12; a 6 de Agosto de 2015, foi ainda constituído um tribunal do acidente médico no Tribunal Popular Distrital de Luzhou City Jiangyang (“瀘州市江陽區人民法院”) um tribunal da mesma natureza no Tribunal Popular de NingLing (“寧陵縣人民法院”) ${ }^{14}$. A criação de todos os tribunais mencionados tem por objectivo resolver, de uma forma concentrada e específica, as disputas médicas que ocorram entre profissionais de saúde e pacientes.

Para melhor compreender o papel que os tribunais do acidente médico desempenham convém conhecer, antes de tudo, a estrutura judicial da República Popular da China.

\footnotetext{
${ }^{10}$ CAI F, Op. Cit.

11 武漢首設醫療糾紛專業審判庭, 健康報, 13 mar 2013 [Acesso em 27 abril 2016]. Disponível em: http://www.jkb.com.cn/news/industryNews/2013/0318/257970.html

12四川綿陽試點醫事法庭, Remin Ribao, 11 jul 2014 [Acesso em 14 jan 2016]. Disponível em: http://politics.people.com.cn/n/2014/0711/c1001-25266870.html

13 瀘州成立川内第二個醫事法庭専審醫療糾紛案件, 成都商報電子版, 21 ago 2015 [Acesso em 14 jan 2016]. Disponível em: http://e.chengdu.cn/html/2015-08/21/content_534362.htm

14 河南首個醫事法庭在商丘甯陵成立 法官懂醫學, 河南法制報, 15 out 2015 [Acesso em 20 jan 2016].

Disponível em: http://news.shangdu.com/102/20151015/8_6028396.shtml
} 
De acordo com o artigo 2.ำ da Lei Orgânica dos Tribunais Populares da República Popular da China ${ }^{15}$, os tribunais da República Popular da China podem ser divididos em três categorias: (1) tribunais populares locais, distribuídos por vários níveis; (2) tribunais populares especiais; (3) tribunais populares supremos. Nos termos do 2.ำ parágrafo do mesmo artigo os tribunais populares locais, por sua vez, também podem ser divididos em três subníveis: (1) tribunais populares básicos; (2) tribunais populares intermédios; (3) tribunais populares superiores.

Os tribunais populares locais distinguem-se dos tribunais populares especiais porque estes últimos são criados tendo em conta o particular âmbito de casos a apreciar, enquanto os tribunais populares locais são criados conforme as regiões administrativas. Por outro lado, também a nomeação dos respectivos funcionários é distinta, bem como a forma da organização destes tribunais. Finalmente, e ao invés do que sucede com os tribunais populares locais, os tribunais populares especiais têm competência para julgar casos de especial natureza, sendo as suas pronúncias especificamente restringidas ao tema desses casos (por exemplo, tribunais militares, tribunais marítimos, tribunais de floresta, etc.), ao passo que os tribunais populares locais são competentes para julgar qualquer litígios ${ }^{16}$.

Posto isto, é de destacar que os tribunais do acidente médico não são tribunais populares especiais, mas sim estruturas criadas dentro dos tribunais populares locais. Contudo, esta opção legal tem suscitado algumas dúvidas. Em nossa opinaão teria sido mais correcto criar os tribunais do acidente médico no seio dos tribunais populares especiais, dada a especialidade e complexidade dos casos em análise. Nesta linha de raciocínio a sua organização, função e competência deveriam ser separadamente reguladas pelo Comité Permanente da Assembleia Popular Nacional da República Popular da China, nos termos do artigo 29.ำ da lei orgânica supramencionada.

\footnotetext{
${ }^{15}$ Sobre este diploma legal em inglês, disponível http://www.lawinfochina.com/display.aspx?id=5623\&lib=law\&SearchKeyword=\&SearchCKeyword=\%d6\%d0\% bb\%aa\%c8\%cb\%c3\%f1\%b9\%b2\%ba\%cd\%b9\%fa\%c8\%cb\%c3\%f1\%b7\%a8\%d4\%ba\%d7\%e9\%d6\%af\%b7\% a8 (Acesso em 26 abril 2016).

16 Informações retiradas da Enciclopédia Baidu (“百度百科”), disponível em: http://baike.baidu.com/view/635925.htm (Acesso em 15 jan 2016).
} 


\title{
Organização e funcionamento dos tribunais do acidente médico
}

\section{Objecto dos tribunais do acidente médico}

Quando um conflito chega ao tribunal do acidente médico é necessário analisar se o caso em concreto envolve um acidente médico, tal como este vem previsto e descrito no artigo 2.. do Regulamento para Tratamento de Acidentes Médicos ${ }^{17}$, que determina que

\begin{abstract}
Para efeitos deste Regulamento, "acidente médico" significa um acidente causado por uma instituição médica ou pelos profissionais médicos ao seu serviço, que resulte em danos na pessoa do paciente devido a faltas médicas resultantes da violação de preceitos legais, administrativos ou departamentais sobre medicina e administração de cuidados de saúde, ou das regras e procedimentos sobre diagnóstico, cura e cuidados médicos" (tradução dos autores) ${ }^{18}$.
\end{abstract}

Uma vez que os tribunais do acidente médico são estabelecidos nos tribunais populares locais em vários níveis, e não existindo uma lei orgânica especial em vigor para os mesmos, é-lhes aplicável a lei orgânica geral, ou seja, a Lei Orgânica dos Tribunais Populares da República Popular da China. Assim sendo, e nos termos do artigo 21. desta lei, os tribunais populares básicos julgam casos de natureza civil e penal na primeira instância, excepto tratando-se de questões expressamente previstas por lei ou decreto. Daqui decorre que os tribunais do acidente médico podem apreciar matérias quer de natureza civil quer de natureza penal.

Para além das devidas indemnizações aos pacientes previstas no artigo $50 .{ }^{\circ}$ do Regulamento para Tratamento de Acidentes Médicos, nos termos dos artigos $55 .^{\circ}$ a $59 .{ }^{\circ}$ deste mesmo Regulamento são previstas sanções administrativas para as instituições hospitalares (como advertência ou cancelamento de licenciamento) e sanções administrativas e criminais para os profissionais de saúde e para os responsáveis pela gestão hospitalar, sendo as sanções administrativas aplicadas pelo Departamento da Administração de Saúde.

\footnotetext{
17 Sobre este regulamento em inglês, disponível em: http://www.npc.gov.cn/englishnpc/Law/200712/14/content_1384186.htm (acesso em 25 de Abril de 2016).

18 "For the purpose of these Regulations, "medical accident" means an accident caused by a medical institution or its medical workers resulting in personal injuries to a patient due to faults in medical activities as a result of violation of the laws, administrative regulations or departmental rules on medical and health administration, or of standards or procedures for diagnosis, cure and nursing" (tradução constante do site http://www.npc.gov.cn/englishnpc/Law/2007-12/14/content_1384186.htm).
} 


\section{Funcionamento e estrutura dos tribunais do acidente médico}

Ao abrigo do artigo 10. da Lei Orgânica dos Tribunais Populares da República Popular da China, os tribunais do acidente médico adoptam o sistema colegial para proceder ao julgamento das causas. Deste modo, são constituídos por três ou mais juízes ou por juízes e jurados populares, sendo presidente um dos juízes, seguindo assim o sistema normalmente adoptado pelos restantes tribunais $\mathrm{O}$ mesmo artigo ainda prevê, no seu segundo parágrafo, que os jurados populares só participam quando envolvem recursos ou protestos. Uma vez que esta segunda figura é especifica do ordenamento jurídico chinês cumpre prestar alguns esclarecimentos. Assim, enquanto os recursos só podem ser apresentados pelas partes, cabe apenas ao Ministério Público Popular recorrer aos protestos, nos termos do segundo parágrafo do artigo $12 .^{\circ}$ do mesmo diploma, o qual se refere a um poder tutelar legalmente conferido ao Ministério Público Popular em representação do Estado. Uma vez que o Ministério Público é um órgão destinado à supervisão legal, nos termos do art. 1. da Lei Orgânica dos Ministérios Públicos Populares da República Popular da China, não pode apresentar recursos em representação do indivíduo, mas apenas protestos, ainda que estes devem ser apresentados conforme o procedimento de recursos.

Outra diferença entre estas figuras - o recurso e o protesto - é que o recurso se destina a defender o interesse próprio das partes, ao passo que o protesto diz respeito aos casos em que o Ministério Público Popular requer ao tribunal popular um novo julgamento por considerar que a decisão judicial foi erradamente proferida (ou seja, de certo modo ainda está ao serviço da tutela das partes) (13) Assim, uma vez verificado um erro definitivo numa decisão judicial, o Ministério Público Popular tem autoridade para recorrer ao protesto conforme o procedimento de supervisão judicial, ao abrigo do terceiro parágrafo do artigo $14 .^{\circ}$ do mesmo diploma.

Como não existe uma regra que determine o exacto número de juízes ou de jurados, os números de juízes nos diversos tribunais do acidente médico já estabelecidos não é uniforme. Por exemplo, o tribunal do acidente médico do Tribunal Popular Intermédio de Mian Yang Shi (“綿陽市中級人民法院”) é composto por cinco juízes sem jurados ${ }^{19}$; mas já no tribunal do acidente médico do Tribunal Popular de NingLing (“寧陵縣人民法院”)

\footnotetext{
19 四川綿陽試點醫事法庭, Cit.
} 
existem três juízes; ao passo que o tribunal do acidente médico do Tribunal Popular Distrital de Luzhou City Jiangyang (“瀘州市江陽區人民法院”) é constituído por oito juízes ${ }^{20}$.

No que toca aos jurados populares, estes são escolhidos a partir da "base de dados de recursos humanos"21 estabelecida no tribunal no qual o tribunal do acidente médico foi estabelecido, a qual, ao que tudo indica, será constituída apenas por especialistas da ciência médica com cargo superior ${ }^{22}$.

Um dos maiores problemas relacionados com a composição dos tribunais do acidente médico prende-se com a dificuldade em encontrar juízes que possuam igualmente conhecimentos sobre a ciência médica. Mas, em boa verdade, este requisito perde alguma importância se tivermos em conta que a existência da base de dados supramencionada implica uma menor necessidade dos conhecimentos da ciência médica por parte dos juízes, porque os jurados escolhidos nessa base de dados desempenham um papel importante, que acaba por colmatar as lacunas de conhecimentos por parte dos juízes. No entanto, certamente que seria desejável que os juízes detivessem pelo menos o conhecimento necessário para avaliação da prova apresentada.

A isto acresce que os juízes dos tribunais do acidente médico, além de proceder aos julgamentos no seio dos tribunais, participam regularmente em processos de conciliação de disputas médicas, organizadas pelas instituições hospitalares, despenhando o papel de conciliadores entre estas e os particulares com vista a eliminar contradições devidas a informações contraditórias e à desconfiança existente entre as partes envolvidas ${ }^{23}$. É evidente que as diligências de conciliação realizadas em hospitais pelos juízes dos tribunais do acidente médico permitem uma resolução mais rápida de litígios e uma maior satisfação das partes sobre a resolução final do litígio, evitando que sobrecarreguem os tribunais do acidente médico.

A submissão de litígios aos tribunais do acidente médico não é obrigatória para o paciente lesado, isto é, o paciente pode optar entre submeter o caso a estes tribunais ou,

\footnotetext{
20 政研室，江陽區法院成立全市首家“醫事法庭”, Luzhou City, 2015 [Acesso em 25 jan 2016]. Disponível em: http://www.Izjyfy.gov.cn/a/sifagongkaipingtai/xinwenxuanchuan/tupianxinwen/20150811294.html

21 Neste momento não temos informações em detalhe sobre a base de dados. A partir das noticias que vão sendo divulgadas sabemos apenas da sua existência e da expectativa de ser constituída apenas por especialistas de ciência médica.

${ }^{22}$ CAl F, Op. Cit.

23 河南首個醫事法庭在商丘甯陵成立 法官懂醫學, artigo publicado em 河南法制報, 15 de Outubro de 2015, at http://news.shangdu.com/102/20151015/8_6028396.shtml (acesso em 20 de Janeiro de 2016).
} 
em alternativa, a um tribunal comum. É evidente que nas cidades em que ainda não foi criado nenhum tribunal do acidente médico os litígios médicos só podem ser resolvidos em tribunais comuns.

Independentemente de submeter os litígios médicos a tribunais comuns ou a tribunais do acidente médico, os regimes jurídicos aplicáveis são os mesmos, pois neste momento ainda não existe um específico diploma legal que apenas seja aplicado nos tribunais do acidente médico. No entanto, o resultado obtido nos tribunais do acidente médico poderá ser efectivamente muito diferente do resultado resultante de um julgamento nos tribunais comuns, dado que os juizes daqueles primeiros têm mais experiência em julgamentos relativos a litígios médicos e, por conseguinte, procedem aos julgamentos de forma mais justa e imparcial. Estas características têm potencial para oferecer uma resposta justa às duas partes em julgamento e, assim, resolver satisfatoriamente o conflito entre as mesmas.

Qualquer das partes pode defender o seu interesse por meio de recurso quando a decisão do tribunal do acidente médico não tenha satisfeito os seus interesses. Os recursos não são obrigatórios, como alias é normal suceder. Ao abrigo do segundo parágrafo do artigo 12.ำ da Lei Orgânica dos Tribunais Populares da República Popular da China,

"[f]rom a judgment or orders of first instance of a local people's courts, a party may bring an appeal to the people's court at the next higher level in accordance with the procedure prescribed by law, and the people's procuratorate may present a protest to the people's court at the next higher level in accordance with the procedure prescribed by law". ${ }^{24}$

A expressão may pela sua interpretação literal, corresponde a um poder facultativo $e$ não a uma obrigatoriedade para as partes, nem para o Ministério Público Popular em casos de protesto (“抗訴”). No entanto, a Lei Orgânica dos Ministérios Públicos Populares da República Popular da China ${ }^{25}$ prevê que, nos termos dos seus artigos 17. e 18.ㄹ, se trata de um dever dos Ministérios Públicos Populares apresentarem protesto, uma vez verificado qualquer erro definitivo nos julgamentos dos tribunais populares. Logo, parece-

\footnotetext{
24 Tradução oficial do site www.lawinfochina.com

25 Lei Orgânica dos Ministérios Públicos Populares da República Popular da China, versão em inglês disponível

http://www.lawinfochina.com/display.aspx?id=6225\&lib=law\&SearchKeyword=\&SearchCKeyword=\%c8\%cb\% c3\%f1\%bc\%ec\%b2\%ec\%d4\%ba\%d7\%e9\%d6\%af\%b7\%a8 (acesso em 26 Abril 2016).
} 
nos que existe uma contradição entre as duas leis orgânicas relativamente à natureza vinculativa ou facultativa de apresentação de protestos.

Nos termos do já referido artigo 12. da Lei Orgânica dos Tribunais Populares da República Popular da China, os tribunais populares (básicos, intermédios e superiores) adoptam o sistema do grau único, no qual as partes podem recorrer ao nível seguinte da instância (o nível da segunda instância depende do nível de tribunais populares nos quais tenha sido julgado o caso em concreto em primeira instância), sendo esta segunda instância a última. Ou seja, os tribunais superiores e o tribunal supremo, quando funcionem como $2^{\underline{a}}$ instância, são na verdade as últimas instâncias (excepto a $1^{\underline{a}}$ instância do tribunal supremo, que já é a última instância; porém, esta excepção não é aplicável aos tribunais do acidente médico porque ainda não foi criado nenhum tribunal do acidente médico no tribunal supremo).

\section{Conclusão: são os tribunais do acidente médico a resolução do problema?}

É verdade que a criação de tribunais do acidente médico na República Popular da China tem sido considerada vantajosa, dado que contribuiu para a eliminação gradual de incidentes relacionados com os "distúrbios dos cuidados de saúde". Este objectivo tem sido conseguido por via da minoração da desconfiança dos pacientes e seus familiares quanto às pronúncias dos tribunais, da resolução concentrada da disputa médica (isto é, sem dispersão por outras questões não relacionadas com o acidente médico em causa) e pela rapidez de resolução dos casos. Contudo, as grandes esperanças que rodearam a sua criação não corresponderam às expectativas relativas à resolução de conflitos médicos na República Popular da China.

Com efeito, a intervenção dos tribunais do acidente médico deveria ser considerada como última ratio e em seu lugar dar preferência à conciliação ou à arbitragem, mecanismos estes que poderiam ser mais eficazes no restabelecimento da relação entre o paciente e os profissionais de saúde.

Para além disso, a criação deste tipo de tribunais só se revela útil depois de a disputa médica efectivamente surgir, ao passo que o principal objectivo deveria ser uma intervenção prévia que evitasse a ocorrência do litígio. Porém, para tal seria necessário intervir nos problemas originários e fundamentais da República Popular da China, 
essencialmente o melhoramento dos recursos de saúde, a gestão de mercado de saúde, o desenvolvimento de seguro de saúde, entre tantos outros

Em suma, embora os tribunais do acidente médico possam resolver temporariamente determinados problemas, a verdade é que para reestabelecer a relação harmónica entre o paciente e profissionais de saúde existem vários outros aspectos a melhorar.

Embora a resolução destes problemas não seja exclusivamente jurídica, certo é que algumas respostas poderão encontrar-se no plano jurídico. Por exemplo, algumas das normas existentes - tais como a Lei dos Profissionais de Saúde da República Popular da China $^{26}$ e o Regulamento para Tratamento de Acidentes Médicos - deveriam ser aperfeiçoadas. Estas são preocupações e fragilidades que se tornam bem patentes na resolução das disputas médicas. A isto acresce que a ausência de sistema consolidado de direito médico na República Popular da China entrava a solução que tanto se anseia. Por conseguinte, a República Popular da China enfrenta ainda diversos desafios no que respeita à melhoria dos seus recursos de saúde e ao aperfeiçoamento do seu sistema jurídico no plano do direito médico.

\section{Referências}

1. Liebman BL. Malpractice Mobs: Medical Dispute Resolution In China. Columbia Law Review. 113(1): 181-264.

2. Kearney J. Why China's 2010 Medical Malpractice Reform Fails to Reform Medical Malpractice. Emory International Law Review. 2012, 26(2): 1039-1078.

3. Wang. H A Dilemma of Chinese Healthcare Reform: How To Re-define Government Roles?, 20 China Econ. Rev. 598, 601-02 (2009).

4. Li H, Wu X, Sun, T. Claims, liabilities, injures and compensation payments of medical malpractice litigation cases in China from 1998 to 2011. BMC Health Services Research. (2014), 14:390. DOI: 10.1186/1472-6963-14-390.

5. Xu W. Violence against doctors in China. Lancet. (30 aug 2014); 384(9945):745.

${ }^{26}$ Sobre esta lei em chinês e em inglês, disponível em: http://www.lawinfochina.com/display.aspx?id=1117\&lib=law\&SearchKeyword=\&SearchCKeyword=\%d6\%d0\% bb\%aa\%c8\%cb\%c3\%f1\%b9\%b2\%ba\%cd\%b9\%fa\%d6\%b4\%d2\%b5\%d2\%bd\%ca\%a6\%b7\%a8 (Acesso em 27 abril 2016). 
6. Zhao L, Zhang XY, Bai GY, Wang YG. Violence against doctors in China. Lancet. (30 aug 2014); 384(9945):744.

7. Yueju L. Violence against doctors in China. Lancet. (30 aug 2014); 384(9945):745.

8. Zhao Z. Income Inequality, Unequal Health Care Access, and Mortality in China. Population and Development Review. (sep 2006), 32(3): 461-483.

9. Chen XY. Defensive medicine or economically motivated corruption? A confucian reflection on physician care in china today. J Med Philos. (2007), 32(6): 635-648.

10. Dai Q. Informed Consent in China: Status Quo and its Future, Medical Law International. (mar 2003), 6(1): 53-71.

11. HE AJ. The doctor-patient relationship, defensive medicine and overprescription in Chinese public hospitals: evidence from a cross-sectional survey in Shenzhen city. Soc Sci Med. (dec 2014), 123: 64-71.

12. Shao TC. The Trial System of Mainland China. Law and Juridical System, (jan de 1994), 3(1): 99-107.

13. Wang HongYu (王洪守), 行政检察監督的法律思考, in Jurists Review (法學家), n.․ 2, 2000, p. 71.

Recebido em: 21/9/2016

Aprovado em: 29/9/2016

\section{Como citar este artigo:}

Raposo VL, long MT. Grandes esperanças: tribunais do acidente médico na República Popular da China. Revista Cadernos Ibero-Americanos de Direito Sanitário. 2016 jul./set, 5(3):223-236. 